\title{
Kaposi's sarcoma: Good outcome with doxorubicin, bleomycin and vincristine sulphate (ABV) chemotherapy and highly active antiretroviral therapy
}

\author{
P B Hesseling, ${ }^{1} \mathrm{MD} ; \mathrm{E}$ Katayi, ${ }^{2} \mathrm{MD} ;$ P Wharin, ${ }^{3} \mathrm{MD} ; \mathbf{R}$ Bardin, ${ }^{2} \mathrm{MD} ; \mathrm{F}$ Kouya, ${ }^{2} \mathrm{MD} ; \mathrm{D}$ Palmer, ${ }^{2} \mathrm{MD} ; \mathrm{M}$ Glenn, ${ }^{2} \mathrm{RNN}$; M Kruger, ${ }^{1} \mathrm{MD}$ \\ ${ }^{1}$ Department of Paediatrics and Child Health, Tygerberg Children's Hospital and Faculty of Medicine and Health Sciences, Stellenbosch University, \\ Cape Town, South Africa \\ ${ }^{2}$ Cameroon Baptist Convention Health Board, Bamenda, Cameroon \\ ${ }^{3}$ Beryl Thyer Memorial Africa Trust, Warkton, UK
}

Corresponding author: P B Hesseling (pbh@sun.ac.za)

\begin{abstract}
There is little published information on effective treatment of Kaposiss sarcoma (KS) in children in low-income countries. We prospectively treated 12 patients with an institutional review board-approved protocol consisting of four monthly courses of doxorubicin (Adriamycin), bleomycin and vincristine sulphate (ABV), with highly active antiretroviral therapy (HAART) plus co-trimoxazole prophylaxis for those who were HIV-positive, with additional vincristine if remission was not achieved after 4 months. Maintenance HAART plus co-trimoxazole was given to all HIV-positive patients. A fine-needle aspirate and CD4+ count were done if possible, and staging was performed according to Mitsuyasu. Eight of ten HIV-positive patients with stage III - IVB disease, and both HIV-negative patients with stage I disease, were in remission after 473 - 1490 (mean 939) days. One patient died after absconding during treatment, and one died from neutropenia-related pulmonary infection. ABV with or without HAART is an effective treatment option for children with KS.
\end{abstract}

S Afr Med J 2017;107(11):952-953. DOI:10.7196/SAMJ.2017.v107i11.12559

There is a memorandum of understanding between the Department of Paediatrics at Tygerberg Children's Hospital, Cape Town, South Africa (SA), and the Cameroon Baptist Hospitals in Cameroon to support the Cameroon Baptist Hospitals' paediatric oncology programme. A recent Cochrane review found a lack of information on the effective treatment of Kaposi's sarcoma (KS) in children with chemotherapy and highly active antiretroviral therapy (HAART). ${ }^{[1]}$ Published treatment guidelines for the management of KS in resource-limited settings include chemotherapy with the single drugs etoposide, thalidomide and vincristine, with two drugs, namely vincristine and bleomycin, and with three drugs, namely doxorubicin (Adriamycin), bleomycin and vinblastine sulphate. ${ }^{[2]}$ An SA multiinstitutional review of HIV-positive children treated with HAART and unspecified chemotherapy schedules reported a $58 \%$ projected 5-year survival rate. ${ }^{[3]}$ In Malawi the combination of vincristine plus bleomycin resulted in a 50\% 1-year survival rate. ${ }^{[4]}$ We report the outcome of a prospective study in children with KS in Cameroon treated with ABV, together with HAART for those who were HIVpositive. This combination of drugs was chosen because they have individual activity against KS, and because they were available in this resource-limited setting.

\section{Methods}

All patients diagnosed with KS at Banso, Mbingo and Mutengene Baptist hospitals in north-west and south-west Cameroon between October 2011 and August 2015 were staged according to Mitsuyasu. ${ }^{[5]}$ Treatment was with an institutional review boardapproved protocol consisting of doxorubicin $10 \mathrm{mg} / \mathrm{m}^{2}$, bleomycin $15 \mathrm{IU} / \mathrm{m}^{2}$ and vincristine $1.5 \mathrm{mg} / \mathrm{m}^{2}$ intravenously (ABV) every 4 weeks for four cycles. Chemotherapy commenced 4 weeks after the initiation of HAART, which was continued indefinitely in HIV-positive patients together with daily co-trimoxazole prophylaxis. HAART consisted of triple antiretrovirals adapted for age and weight according to World Health Organization guidelines. Chemotherapy was given at 4-week intervals to limit toxicity. Vincristine $1.5 \mathrm{mg} / \mathrm{m}^{2}$ was continued every 4 weeks for four doses if remission was not achieved. A fine-needle aspirate (FNA) and CD4+ count were recommended investigations. Informed parental consent was obtained. Follow-up was achieved by outpatient visits, telephone calls and home visits. Treatment was free.

\section{Resulits}

Twelve patients, 10 boys and 2 girls aged $2-11$ (median 7) years, were treated. Two HIV-negative patients presented with a localised skin lesion and localised lymphadenopathy, respectively. The HIV-positive patients presented with stage III $(n=3)$, IVA $(n=3)$ and IVB $(n=4)$ disease. An FNA was performed in 7 patients, and a CD4+ count in 7 (median 144 (range 11 - 946) cells $/ \mu \mathrm{L}$ ). One HIV-negative patient received additional vincristine. Two deaths occurred, both in HIV-positive patients. One died from febrile neutropenia and pulmonary disease on day 48 , while the other did not return after two courses of ABV, his family deciding in favour of traditional medicine, and died of progressive KS on day 390 . Both these patients had a CD $4+$ count of $<100 / \mu L$. Eight HIV-positive patients were in remission after 1.5 - 50 (median 30) months' follow-up at the time of writing, and the 2 HIV-negative patients were in remission after 19 and 37 months' follow-up, respectively. Table 1 sets out details of age, sex, stage, FNA, CD4+ count, treatment and outcome (December 2016). No patients were lost to follow-up. 
Table 1. Clinical and laboratory findings in children with Kaposi's sarcoma

\begin{tabular}{|c|c|c|c|c|c|c|c|c|}
\hline Case & $\begin{array}{l}\text { Age (yr), } \\
\text { sex }\end{array}$ & Stage & HIV & $\begin{array}{l}\text { CD4+ } \\
\text { count } \\
(\text { cells } / \mu \mathrm{L})\end{array}$ & FNA & Treatment & Status & $\begin{array}{l}\text { Follow-up } \\
\text { (mo) }\end{array}$ \\
\hline 1 & $7, \mathrm{M}$ & I & - & & KS & $\mathrm{ABV}$ & CR & 37 \\
\hline 2 & $6, \mathrm{M}$ & IVB & + & 240 & KS & HAART/ABV & $\mathrm{CR}$ & 44 \\
\hline 3 & $7, \mathrm{M}$ & IIIB & + & 27 & NT & HAART/ABV & $\mathrm{CR}$ & 24 \\
\hline 4 & $6, \mathrm{M}$ & IVB & + & 11 & KS & HAART/ABV & Died & 13 \\
\hline 5 & $7, \mathrm{~F}$ & IIIB & + & 144 & KS & HAART/ABV & $\mathrm{CR}$ & 49 \\
\hline 6 & $2, \mathrm{M}$ & IVB & + & NT & KS & HAART/ABV & $\mathrm{CR}$ & 50 \\
\hline 7 & $7, \mathrm{M}$ & IVB & + & 946 & KS & HAART/ABV & $\mathrm{CR}$ & 22 \\
\hline 8 & $4, \mathrm{M}$ & IVA & + & 54 & NS & HAART/ABV & Died & 1.5 \\
\hline 9 & $11, \mathrm{M}$ & I & - & & NT & $\mathrm{ABV}+$ & $\mathrm{CR}$ & 19 \\
\hline 10 & $9, \mathrm{M}$ & IIIB & + & NT & NT & HAART/ABV & $\mathrm{CR}$ & 49 \\
\hline 11 & $12, \mathrm{M}$ & IVB & + & NT & NT & HAART/ABV & $\mathrm{CR}$ & 36 \\
\hline 12 & $11, \mathrm{~F}$ & IVB & + & 619 & NT & HAART/ABV & CR & 16 \\
\hline
\end{tabular}

\section{Discussion}

Although the incidence of $\mathrm{KS}$ in some African countries is decreasing because of HAART, it remains an important cause of childhood cancer. ${ }^{[6]}$ No effective chemotherapy for patients in lowincome countries has been published to date. We used the above chemotherapy agents because of their individual efficacy and their availability. Although the number of patients is small, treatment with $\mathrm{ABV}$ with or without HAART achieved good medium-term survival in HIV-positive and HIV-negative patients, with one possible treatment-related death.

\section{Conclusion}

Four cycles of ABV plus HAART in HIV-positive patients achieved good medium-term survival in patients with KS.

Acknowledgements. The authors thank research nurses Patience Nfor and Comfort Kimbi for data collection.
Author contributions. All the authors were actively involved in protocol design, patient diagnosis and management and the preparation of the manuscript.

Funding. Funding was received from the Swiss Cancer League, Beryl Thyer Memorial Africa Trust and World Child Cancer.

Conflicts of interest. None. 1. Anglemyer A, Agarwal AK, Rutherford W. Treatment of Kaposi sarcoma in children with
HIV-1 infection. Cochrane Database Syst Rev 2014, Issue 1. Art. No.: CD009826. https://doi. org/10.1002/14651858.CD009826.pub2

2. Molyneux E, Davidson A, Orem J, et al. The management of children with Kaposi sarcoma in resource limited settings. Pediatr Blood Cancer 2013;60(4):538-542. https://doi.org/10.1002/pbc.24408

3. Davidson A, Wainwright R, Stones DK, et al. Malignancies in South African children with HIV. I Pediatr Hematol Oncol 2014;36(2):111-117. https://doi.org/10.1097/MPH.ObO13e31829cdd49 Chagaluka G, Stanley C, Banda K, et al. Kaposiss sarcoma in children: An open randomised trial of vincristine, oral etoposide and a combination of vincristine and bleomycin. Eur J Cancer 2014;50(8):1472-1481. https://doi.org/1016/j.ejca.2014.02.01

. Mitsuyasu RT. Clinical variants and staging of Kaposi's sarcoma. Semin Oncol 1987:14(suppl 3):13-18. Steliarova-Foucher E, Colombet M, Ries LAG, et al., eds. International Incidence of Childhood Cancer,
vol. II (electronic version). Lyon: International Agency for Research on Cancer 2017, http://iicciarc fr. (accessed 16 February 2017)

Accepted 28 July 2017. 